\title{
Cardiogenic shock due to Takotsubo cardiomyopathy following thyroidectomy
}

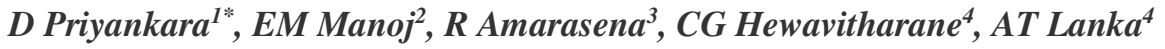 \\ Senior registrar in Critical Care Medicine ${ }^{I^{*}}$, Consultant Intensivist ${ }^{2}$, Consultant Anaesthetist ${ }^{3}$, Senior \\ Registrar in Anaesthesia ${ }^{4}$, National Hospital of Sri Lanka, Sri Lanka.
}

\begin{abstract}
Takotsubo cardiomyopathy is characterized by transient left ventricular dysfunction in the absence of atherosclerotic disease. A $63 \mathrm{yr}$ old female with multiple autoimmune disorders was admitted to intensive care unit with severe hypotension and hypoxic respiratory failure following total thyroidectomy. During her evaluation, her 2D echocardiogram showed good basal contractions with severe mid and apical hypokinesia and an ejection fraction of $35 \%$. Her coronary angiogram showed normal epicardial coronaries and evidence of apical ballooning suggestive of TCM. Its recognition is important for prognostic evaluation and treatment considerations. Furthermore, the relationship between autoimmunity and TCM needs to be evaluated further.
\end{abstract}

Keywords: Takotsubo cardiomyopathy; cardiogenic shock; apical ballooning syndrome; stress induced cardiomyopathy; left ventricular dysfunction

\section{Introduction}

Takotsubo cardiomyopathy (TCM) is a wellknown but an under-diagnosed disease characterized by transient left ventricular dysfunction in the absence of atherosclerotic disease. TCM is thought to be triggered due to catecholamine release especially in postmenopausal females. ${ }^{1}$ We report a case of TCM during immediate postoperative period which made a dilemma, mimicking an acute coronary event.

\section{Case history}

A 63yr old ASA 2 lady was admitted to the surgical intensive care unit due to respiratory failure and hypotension following thyroidectomy. She had type 2 diabetes, autoimmune haemolytic anaemia ( $\mathrm{IgG})$, autoimmune thyroiditis and vitamin B12 deficiency. Her pre-operative thyroid function tests, haemoglobin, renal functions and electrolytes were within normal limits.

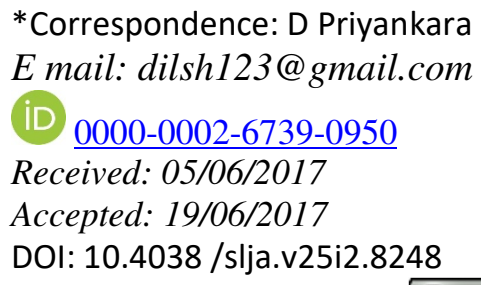

*Correspondence: D Priyankara

E mail:dilsh123@gmail.com

iD 0000-0002-6739-0950

Received: 05/06/2017

Accepted: 19/06/2017

DOI: 10.4038 /slja.v25i2.8248

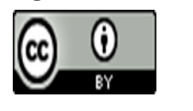

She underwent elective total thyroidectomy for suspected follicular cell proliferation. General anaesthesia was induced with intravenous fentanyl $100 \mu \mathrm{g}$ and $120 \mathrm{mg}$ of propofol and received atracurium $25 \mathrm{mg}$ i.v. Anaesthesia was maintained with $33 \% \quad \mathrm{O}_{2}, 66 \% \mathrm{~N}_{2} \mathrm{O}$ and $1 \%$ isoflurane. Intravenous morphine $9 \mathrm{mg}$ was give 3 mins prior to the incision. Intermittent positive pressure ventilation was continued and agent monitoring was done. The surgery was uneventful and haemodynamics were stable during surgery. Her blood pressure (BP) ranged from $130 / 80 \mathrm{mmHg}$ to $100 / 70 \mathrm{mmHg}$ during surgery and the heart rate (HR) ranged from 62$85 / \mathrm{min}$. At the end of surgery, when the surgical clips were been applied the monitor displayed a sudden rise in BP up to 220/110mmHg.This was attributed to light anaesthesia or pain and inhaled Isoflurane was increased and i.v morphine $5 \mathrm{mg}$ was given. Over next 10 minutes the BP returned to a level of $110 / 75 \mathrm{mmHg}$ with HR coming down to 70 beats $/ \mathrm{min}$. $\mathrm{O}_{2}$ saturation of $100 \%$ was maintained with $50 \% \mathrm{O}_{2}$. Once stabilized she was extubated and transferred to the recovery area. After 30mins following extubation she developed sudden onset dyspnoea and hypotension. Her BP was $70 / 50 \mathrm{mmHg}$ and she had a persistent tachycardia of 130/min. Pulse oxymeter saturation was $60 \%$ with $60 \% \mathrm{O}_{2}$. She was reintubated and immediately transferred to ICU.

Her BP was maintained with dobutamine $(20 \mu \mathrm{g} / \mathrm{kg} / \mathrm{min})$, noradrenaline $(0.5 \mu \mathrm{g} / \mathrm{kg} / \mathrm{min})$ 
and epinephrine $(0.5 \mu \mathrm{g} / \mathrm{kg} / \mathrm{min})$. There were pulmonary bi-basal fine crepitations. Her jugular venous pressure was $15 \mathrm{cmH}_{2} \mathrm{O}$. ECG showed T wave inversions in the anterior leads. Troponin I titer was $0.1(<0.06 \mathrm{ng} / \mathrm{mL})$.

Figure 1: Chest X-ray obtained in the ICU

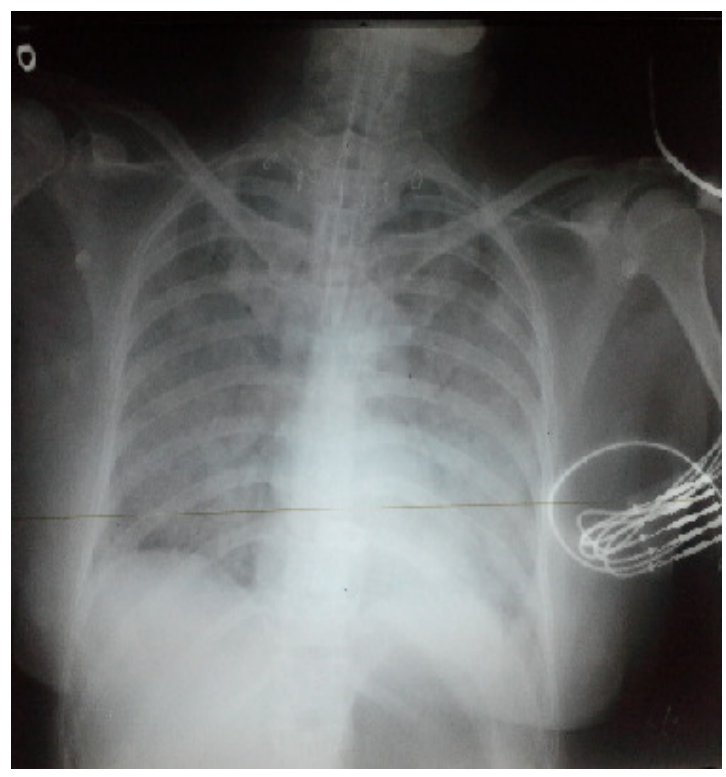

Figure 2 (a): Ventriculogram in diastole

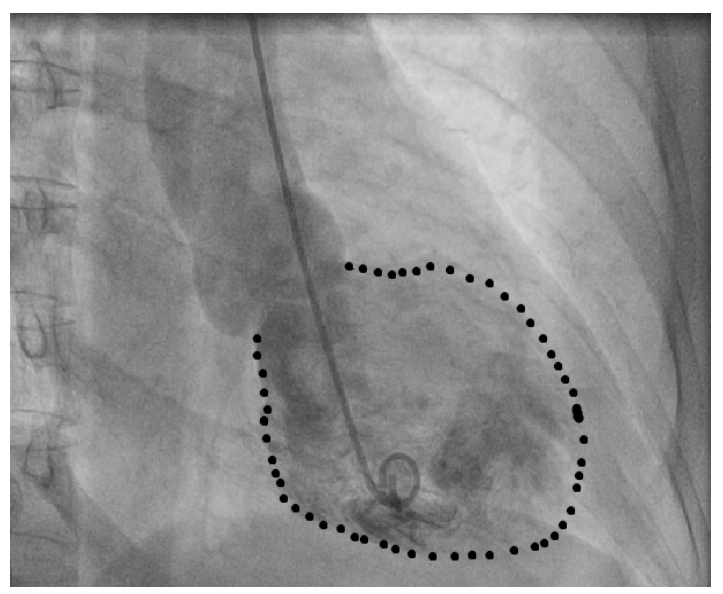

2(b): Ventriculogram in systole

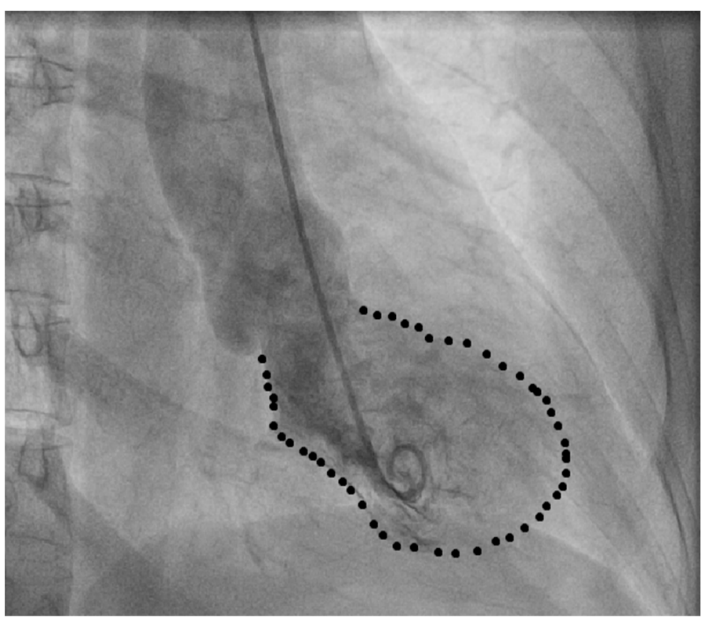

Chest x-ray (Figure 1) showed bilateral alveolar shadows. 2D echocardiogram (ECHO) revealed good basal contractions with severe mid and apical hypokinesia and an ejection fraction of $35 \%$.

Negative pressure pulmonary oedema (PO) and acute coronary syndrome (ACS) were considered as the initial differential diagnoses. The ECG changes and positive troponin suggested, hypotension was of cardiac origin. She was ventilated on pressure controlled mode with positive end expiratory pressure (PEEP) of 10$12 \mathrm{cmH}_{2} \mathrm{O}$. PO slowly responded to i.v furosemide. She was immediately referred to cardiology team. The findings of 2D echocardiogram lead us to think of the possibility of TCM. Her coronary angiogram showed normal epicardial coronaries and the left ventriculogram showed (Figure 2a and Figure 2b) akinesis of the distal anterior and apical regions, and ballooning of the apex during systole, with relative sparing of the basal segment of the left ventricle. Based on the abnormal ECG changes, non-occlusive coronary arteries, mild elevation of cardiac markers, and apical left ventricular systolic dysfunction, the diagnosis of TCM was made. She was transferred to coronary care unit and inotropes and vasopressors were gradually tailed off. There was a dramatic improvement in her BP and HR over a period of $12 \mathrm{hrs}$ from the point at which inotropes were tailed off. After the $3^{\text {rd }}$ day her ECG became normal and 2D ECHO showed normal left ventricular function. 


\section{Discussion}

TCM causes transient left ventricular apical hypokinesia with hyperkinetic basal segments. It has been well documented in situations of severe physical or psychological stress. ${ }^{2}$ It is thought to be mainly due to an acute adrenergic surge which causes transient diffuse vasospasm of coronary microcirculation. Theories include coronary spasm, microvascular dysfunction, transient excessive levels of catecholamine, and abnormal response to epinephrine and norepinephrine. ${ }^{3}$ Gianni and colleagues showed TCM is more common among post-menopausal females, which thought to be due to altered endothelial functions due to lack of oestrogen. ${ }^{4}$

There are limited number of cases of TCM related to anaesthesia and the post-operative period. ${ }^{5,6}$ The "stress response during surgery through direct activation of the sympathetic nervous system" can last for 3 to 4 days postoperatively. In our patient, the event could have precipitated most probably due to light anaesthesia, which lead to sudden sympathetic discharge.

Lim T and colleagues reported a case of TCM in combination with autoimmune polyendocrine syndrome type II (APS II). ${ }^{7}$ Furthermore, Lee SJ and colleagues showed influence of thyroid autoimmunity on myocardial contractility in stress cardiomyopathy. ${ }^{8}$ Our patient had several autoimmune conditions. All these raise questions about relationship between autoimmune disease and pathogenesis of TCM.

The diagnosis is based on modified Mayo Clinic criteria (Table 1). TCM mimics ACS and ECG findings cannot differentiate between the two diagnoses. Therefore, TCM must be diagnosed carefully as these two disorders have a different pathogenesis, management, and outcome. Typical findings are disturbances of segmental contractility (apical hypokinesia or akinesia), with normal epicardial coronary arteries.

1. Transient left ventricular hypokinesis, akinesis, or dyskinesia with or without apical involvement. The regional wall motion abnormalities typically extend beyond a single epicardial coronary distribution. It is frequently, but not always, a stressful trigger.

2. Absence of obstructive coronary artery disease or angiographic evidence of acute plaque rupture
3. New electrocardiogram changes: ST-segment elevation and/or T-wave inversion or modest elevation in cardiac troponin levels.

4, Absence of pheochromocytoma and myocarditis

Table 1: Mayo clinic diagnostic inclusion criteria of Takotsubo cardiomyopathy

The management of TCM is mainly supportive and has a good prognosis in patients without any major co-morbidity, especially if they survive the acute phase. Even though dopamine and dobutamine is used in hypotensive patients, it is recommended that dobutamine should be avoided in patients with severe systolic dysfunction or left ventricular out flow tract obstruction with hypotension and shock. ${ }^{9}$ Therefore, the accurate diagnosis is important in making such alterations in the management.

\section{Conclusion}

This case highlights the importance of TCM as a differential diagnosis in patients demonstrating myocardial dysfunction in perioperative period especially in post-menopausal females. Since the diagnosis, management and prognosis is different from ACS and the recurrence rate is approximately $3.5 \%$ it is important to consider TCM in such situation. Furthermore, the relationship between autoimmunity and TCM needs to evaluate further.

\section{References}

1. Tsuchihashi $\mathrm{K}$, Ueshima $\mathrm{K}$, Uchida $\mathrm{T}$, et al. Transient left ventricular apical ballooning without coronary artery stenosis: a novel heart syndrome mimicking acute myocardial infarction. Journal of the American College of Cardiology. 2001; 38: 11-8.

https://doi.org/10.1016/S0735-1097(01)01316-X

2. Bybee KA, Kara T, Prasad A, et al. Systematic review: transient left ventricular apical ballooning: a syndrome that mimics ST-segment elevation myocardial infarction. Ann Intern Med. 2004; 141:858-65.

https://doi.org/10.7326/0003-4819-141-11200412070-00010

PMid: 15583228

3. Shahbaz R, Refai S. TakoTsubo Cardiomyopathy a Short Review: Curr Cardiol Rev. 2013 Aug; 9(3): 191-196. https://doi.org/10.2174/1573403X11309030003 PMCid:PMC3780344

4. Gianni M, Dentali F, Grandi AM, et al. Apical ballooning syndrome or takotsubo 
Priyankara et al. Sri Lankan Journal of Anaesthesiology: 25(2):118-121(2017)

cardiomyopathy: a systematic review. Eur Heart J. 2006; 27(13):1523-1529.

https://doi.org/10.1093/eurheartj/eh1032

PMid:16720686

5. Gavish D, Rozenman Y, Hafner R, et al. Takotsubo cardiomyopathy after general anesthesia for eye surgery. Anesthesiology. 2006; 105 (3):621-623.

https://doi.org/10.1097/00000542-200609000$\underline{00029}$

PMid:16931998

6. Barbara B, Ferne C. Early Postoperative Takotsubo Cardiomyopathy: A Case Report: AANA Journal. 2011; 79 (3):181-188

7. Tingsong Lim, Hironori Murakami, Kentaro Hayashi, et al. Takotsubo cardiomyopathy associated with autoimmune polyendocrine syndrome II. Journal of Cardiology. 2009; 53: 306-310. https://doi.org/10.1016/j.jicc.2008.08.005 PMid:19304138

8. Lee SJ, Kang JG, Ryu OH, et al. The relationship of thyroid hormone status with myocardial function in stress cardiomyopathy. Eur J Endocrinol. 2009; $160 \quad$ (5): 799-806. https://doi.org/10.1530/EJE-08-0808

PMid:19221174

9. Dorfman TA, Iskandrian AE. Takotsubo cardiomyopathy: state-of-the-art review. J Nucl Cardiol.2009; 16(1):122-134.

https://doi.org/10.1007/s12350-008-9015-3

PMid:19152137 